\title{
Observations on the Distribution of Certain Tobacco Smoke Components with Respect to Particle Size*
}

\author{
by Gerald P. Morie and Madelyn S. Baggett \\ Research Laboratories, Tennessee Eastman Company, Division of Eastman Kodak Company, \\ Kingsport, Tennessee, U.S.A.
}

\section{INTRODUCTION}

Over the years a number of different techniques have been used to determine the particle size distribution of smoke. The techniques may be generally divided into two types of measurements: [1] those in which the smoke particles are isolated or collected and measured and [2] those in which a physical property of the stabilized or diluted aerosol is measured.

Warner et al. reported a number mean diameter of $0.3 \mu$ as determined by a cascade impactor (1). Keith and Derrick used a conifuge to collect and fractionate diluted cigarette smoke; they reported a number mean diameter of $0.2 \mu$ (2). Holmes, Hardcastle, and Mitchell used a cascade impactor and a gravity settling chamber for the determination of smoke particle size. They found mass mean diameters of $1.33 \mu$ and $0.94 \mu$ by the gravity settling chamber and cascade impactor, respectively (3). Leonard and Kiefer (4) found a mass mean diameter of $0.76 \mu$ and a coagulation rate of $1 \times 10^{-9} \mathrm{ml} / \mathrm{s}$ by means of a cascade impactor.

Overton (5) reported a number mean diameter of $0.4 \mu$ based on low-angle light scattering of diluted smoke. Recent refinements in the light scattering techniques were made by Okada and Matsunuma (6) and the use of a highly focused laser beam was employed by Hill and Adams (7). Both of these groups reported a number mean diameter of $0.18 \mu$ for cigarette smoke particles.

The fractionation of tobacco smoke by particle size and the subsequent determination of specific chemical compounds in these fractions has received little attention, probably because of the complexity of such a project. It has been postulated that soon after nucleated smoke aerosol particles are formed, chemical differences exist among particles of different sizes (8). In general, it has been thought that the coagulation rate of the tobacco smoke aerosol was sufficiently rapid to eliminate any differences. However, Leonard and Kiefer

\footnotetext{
* Presented at the 6th International Tobacco Scientific Congress (Coresta) held in Tokyo in November 1976.
}

showed that the rate of coagulation of undiluted smoke is slow $\left(1 \times 10^{-9} \mathrm{ml} / \mathrm{s}\right)$ and plays only a minor role in particle growth (4). Therefore, it is possible that differences in chemical composition of different sizes of aerosol particles still exist as these particles leave the cigarette and enter the filter. Filtration mechanisms of cigarette smoke are dependent on the size of the aerosol droplets (9). Inasmuch as the particle size distribution of an aerosol is altered by the parameters of the filter, cigarette butt length, and type of tobacco (8), a compound or group of compounds might be selectively removed owing to the selective filtration of a certain particle size.

Few studies have been directed at the determination of the chemical composition with respect to particle size. Berner and Marek (10) used a Goetz aerosol spectrometer to determine the particle size distribution of nicotine and potassium. They found that nicotine exhibited a broad maximum between 0.3 and $0.6 \mu$. The distributions of scopoletin, neophytadiene and nicotine were determined by means of a conifuge by Owen, Westcott and Woodman (8). They reported nearly twice the concentration of nicotine in the $0.6 \mu$ particles over the $0.2 \mu$ particles but fewer differences in the other two compounds. Jones, Lugton, Massey and Riobardson (11) added decachlorobiphenyl and radioactive n-hexadecane, dotriacontane and nicotine to cigarettes to determine if the size distributions of these added com. pounds were similar to that of the total particulate matter (TPM). They found that the particle size distributions of these compounds were similar to that of the TPM; some noticeable differences occurred in the very small particle size range.

Previous reports on the composition of tobacco smoke versus particle size are based on methods which involve dilution of smoke with air, and only a limited number of compounds were determined. The objective of this work was to separate undiluted cigarette smoke into several fractions based on the size of the aerosol particles and to determine the concentration of five organic smoke compounds and one inorganic compound in these fractions. 


\section{EXPERIMENTAL}

\section{Instrumentation}

A cascade impactor (12) was used to fractionate the cigarette smoke according to particle size. The impactor (Figure 1) is composed of four jets; each jet is followed by a glass slide. The jet diameter and the jet to slide distance determines the size of the particles that will be trapped on the slide. If the momentum of the particles is great enough, they will overcome the drag exerted by the airstream as it moves around the slide, and they will impact on the slide. Smaller particles are forced through orifices of decreasing diameter so that they acquire enough momentum to impact on a slide. The cascade impactor used in this study has four stages, which have cut off ranges for particles with diameters of $1.00 \mu, 0.75 \mu, 0.50 \mu$, and $0.25 \mu$ followed by a Cambridge pad.

A Filtrona Model 200 smoking machine was used to take the initial puffs on cigarettes. A Varian Model 1860 gas chromatograph equipped with a flame ionization detector and glass capillary columns was used for the determination of the organic compounds. A Perkin-Elmer Model 134 spectrophotometer was used to measure the absorbance of TPM solutions. A PerkinElmer Model HGA 2100 flameless atomic absorption spectrometer was used for the determination of copper in TPM.

\section{Smoking Procedure}

The cascade impactor was connected to a solenoid and a vacuum pump, so that a 2 -second, $35 \mathrm{ml}$ puff of undiluted smoke was taken once a minute. Kentucky 1R1 cigarettes were used for the particle size analysis. Three puffs were taken using a Filtrona Model 200 smoking machine. The TPM from the fourth puff or the fourth and fifth puffs was collected on the glass plates of the cascade impactor.

\section{Figure 1. Cascade Impactor.}

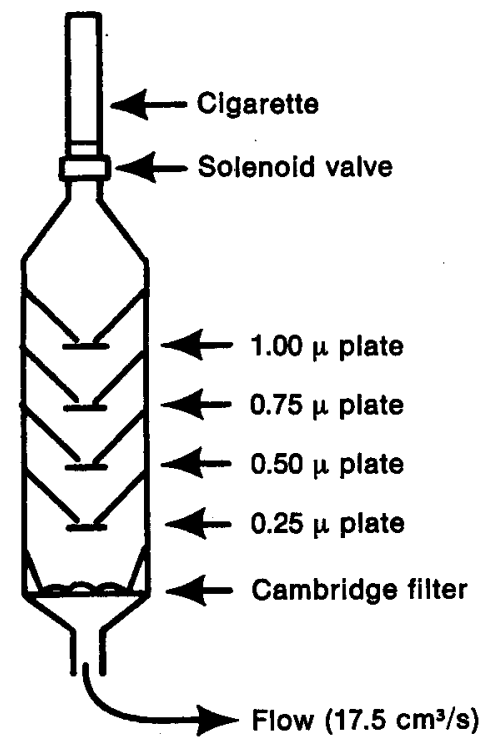

\section{Determination of Organic Compounds}

An internal standard solution of $38 \mu \mathrm{g}$ n-octadecane per $\mathrm{ml}$ of dimethylformamide (DMF) was prepared. Immediately after the particulate matter was collected, $10 \mu \mathrm{l}$ of the internal standard solution was placed on one of the glass slides and the TPM solution was quickly transferred by capillary action to a melting point capillary. This technique minimized the evaporation of solvent and smoke compounds. A syringe was used to withdraw $0.2 \mu \mathrm{l}$ of the dissolved TPM sample which contained the internal standard. This aliquot was injected onto a $500 \mathrm{ft}$. glass capillary gas chromatographic column coated with OV-101 dimethyl silicone oil. The column temperature was held for $10 \mathrm{~min}$ at $115^{\circ} \mathrm{C}$ and then programmed at $1.5^{\circ} / \mathrm{min}$ to $200^{\circ} \mathrm{C}$.

Only one plate was analyzed for each cigarette, because the more volatile smoke components evaporated rapidly. Five compounds - indole, nicotine, diethylphthalate, norphytene and neophytadiene - were used to study the composition of cigarette smoke with respect to aerosol particle size.

The chromatographic peak heights of these five smoke components and that of n-octadecane were measured, and the peak height ratio for each of the five components to octadecane was calculated. The average peak height ratio for each compound compared to the standard was determined for each plate from at least three separate smoke samples. The total amount of each compound present on all plates was obtained by adding the average peak height ratio for each compound. Then the percentage of each compound present per plate was calculated by dividing the average ratio for each compound for each plate by the total ratio of that compound for all plates (Table 1). This method is valid when the components have a linear response in a flame ionization detector.

\section{Measurement of TPM versus Particle Size}

The distribution of TPM on the cascade impactor was determined on the fourth, or combined fourth and fifth puffs from a Kentudky 1R1 cigarette. Each plate was rinsed with methanol, and the solution was diluted to $10 \mathrm{ml}$ with methanol. The absorbance from the TPM on each plate versus that of a methanol blank was read at $310 \mathrm{~nm}$. Previous workers $(13,14)$ have shown that the absorbance of the TPM solution in this region is proportional to the amount of TPM. The absorbances of all four plates were determined for both the fourth and combined fourth and fifth puffs. The percentage of TPM present on each plate was calculated as the percentage of total absorbance contributed by each plate. The TPM distribution was virtually the same for both one and two puffs.

The weight percentage of TPM and the weight percentage of each compound for each plate was known. The ratio of these percentages (compound/TPM) for ead plate was calculated. The ratio for each compound versus particle size was plotted. 
Figure 2. Distribution of TPM, indole, nicotine, and neophytadlene with reepect to aerosol particle elze.

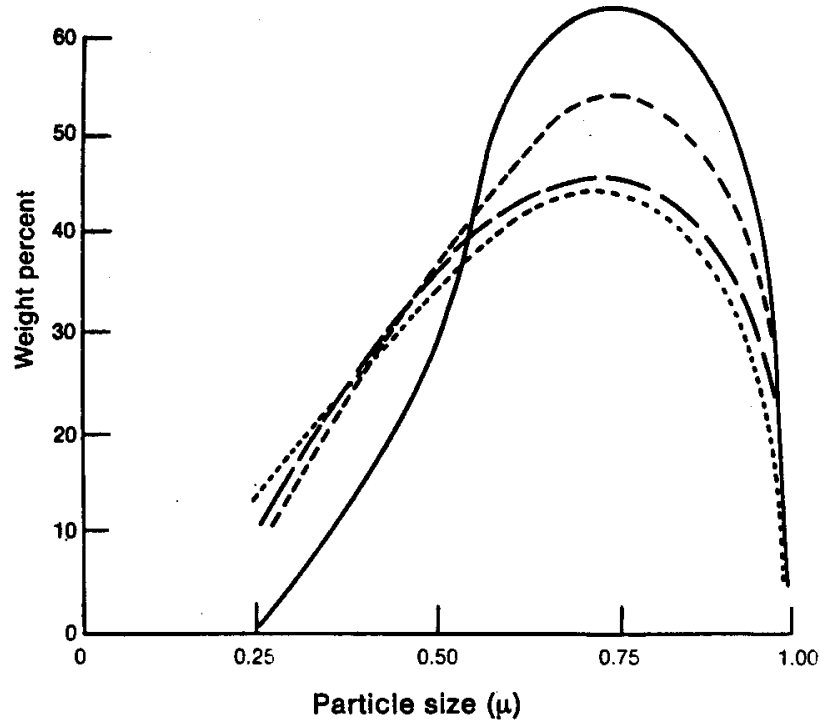

TPM:

Indole:

Nicotine

Neophytadiene:

Figure 3. Ratio of weight percent Indole to weight percent TPM.

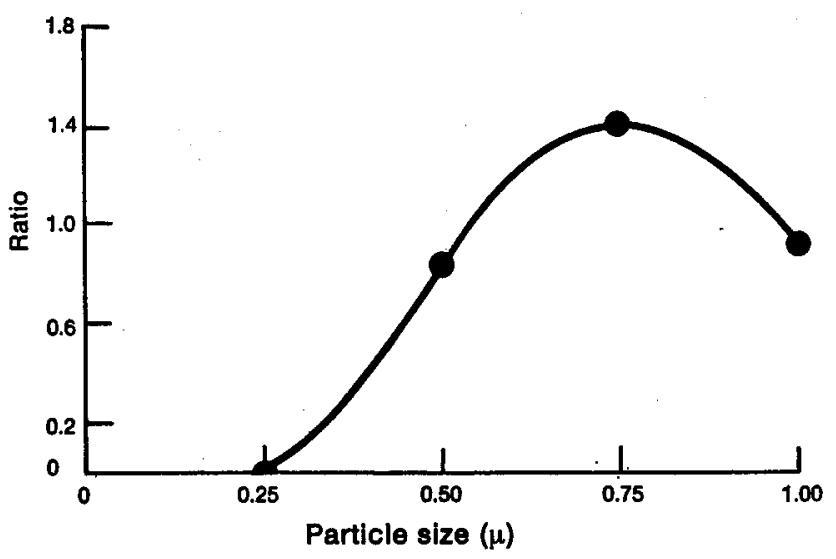

Figure 4. Ratio of weight percent nicotine to weight percent TPM.

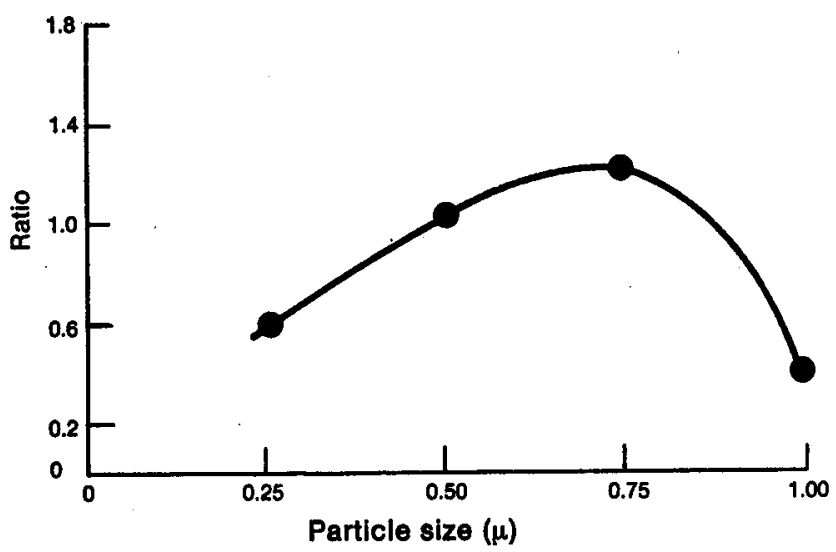

Figure 5. Ratlo of weight percent diothyiphthalate to

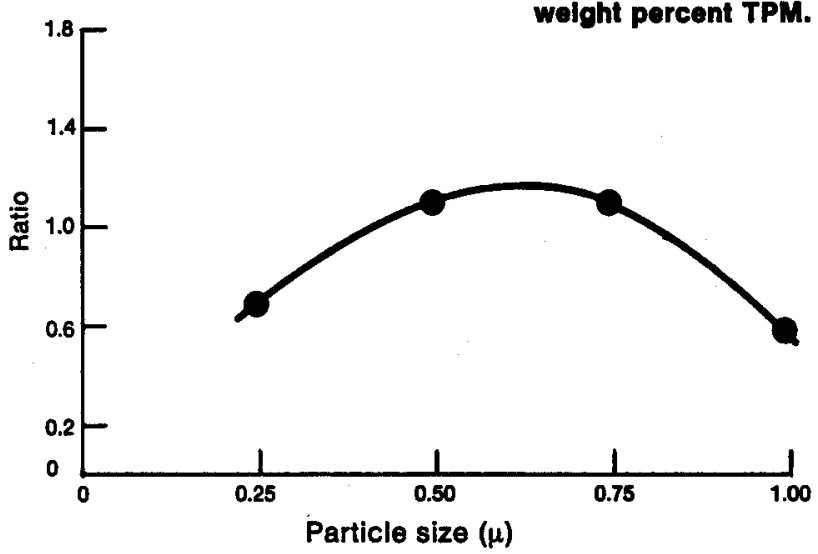
welght percent TPM.

Figure 6. Ratio of weight percent norphytene to weight

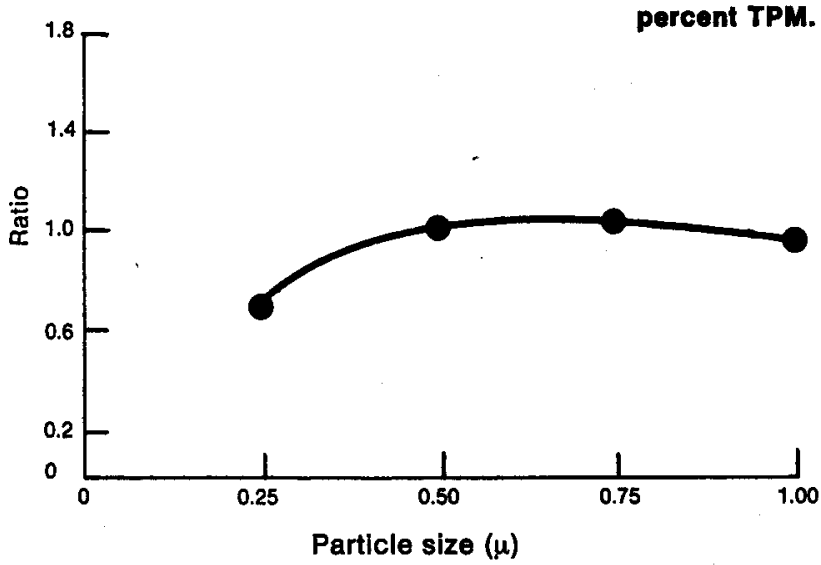

Figure 7. Ratio of weight percent neophytadiene to

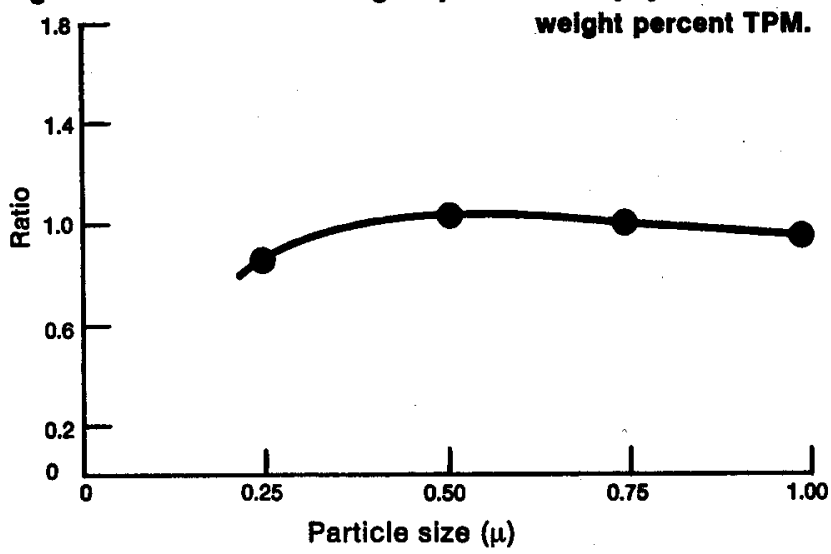

Figure 8. Ratio of weight percent copper to weight per-

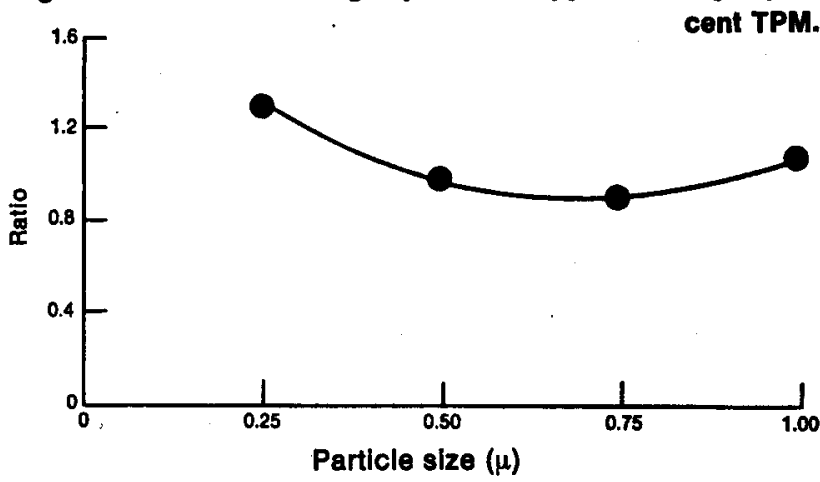


Distribution of Copper versus Particle Size

The particle size distribution of copper in cigarette smoke was determined on the fourth and fifth puffs of a Kentudky 1R1 cigarette with the cascade impactor under the conditions given previously. A Perkin-Elmer flameless atomic absorption spectrometer with the sensitivity to determine copper at the nanogram level was used. Known solutions of copper in isopropanol were prepared and used to calibrate the instrument using the $3247.5 \AA$ absorption line for copper. The $0.25 \mu$ and $1.00 \mu$ plates were rinsed with $0.5 \mathrm{ml}$ isopropanol; the $0.50 \mu$ and $0.75 \mu$ plates were rinsed with $1.0 \mathrm{ml}$ isopropanol. Triplicate $50 \mu \mathrm{l}$ aliquots of each plate were analyzed. The amount of copper present in two puffs on each plate was averaged from three cigarettes. The weight percent of copper present per plate was calculated, and the ratio of weight percent copper to weight percent TPM was determined and plotted versus particle size.

\section{Effect of Filters on the Size Distribution of Nicotine}

The differences in the particle size distribution of TPM and nicotine in filtered and unfiltered cigarettes were also observed. A popular domestic filter cigarette was compared to a control made from a tobacco column of the same cigarette in place of the filter. The fourth puff was used for both the spectrophotometric determination of the TPM and the gas chromatographic determination of nicotine. Each point on the graphs is an average of three separate analyses.

The fourth puff of smoke from five cigarettes was collected on a Cambridge pad, and the pad was extracted with methanol. The extract was analyzed spectrophotometrically. The TPM from four groups of filtered and unfiltered cigarettes was analyzed and the average TPM removal was calculated.

\section{RESULTS AND DISCUSSION}

The percentages of each of the six smoke components studied and of the TPM on the four different plates of the cascade impactor is given in Table 1. Each value listed is an average of at least three separate determinations. The reproducibility of the method was approximately $\pm 2 \%$ of the values listed in Table 1 . A graphical comparison of the distribution of the five organic compounds with respect to particle size is given in Figure 2. The distribution of TPM versus particle size is illustrated by the bottom (dotted) line.

All of the organic compounds deviate from this line in the same way, but to different extents. All of these compounds are present in higher concentrations in the medium size particles $(0.5 \mu$ and $0.75 \mu)$ than in the smaller or larger particles. These data indicate the following trend: The higher the vapor pressure of the organic smoke compound, the higher the concentration in the medium size aerosol particles. Stated another way, the more volatile compounds tend to form a
Table 1. Welght percentages of smoke components versus particle size.

\begin{tabular}{l|c|c|c|c}
\hline \multirow{2}{*}{ Component } & \multicolumn{5}{c}{ Composition, weight percent } \\
\cline { 2 - 5 } & $0.25 \mu$ & $0.50 \mu$ & $0.75 \mu$ & $1.00 \mu$ \\
\hline Indole & 0 & 28 & 62 & 10 \\
Nicotine & 7 & 34 & 54 & 4 \\
Diethylphthalate & 8 & 37 & 49 & 7 \\
Norphytene & 8 & 34 & 47 & 11 \\
Neophytadiene & 10 & 34 & 45 & 11 \\
Total particulate & 11 & 33 & 45 & 11 \\
matter (TPM) & 15 & 33 & 40 & 12 \\
Copper & & & & \\
\hline
\end{tabular}

narrow size distribution, more nearly like a monodisperse aerosol. This probably occurs because the more volatile compounds evaporate rapidly from the small particles and recondense on the most numerous particles, namely those in the $0.5 \mu$ to $0.75 \mu$ diameter range.

The data can also be displayed in still another form. The ratio of the weight percent of each compound to the weight percent TPM was calculated for each plate of the cascade impactor. These data are shown in Figures 3 through 8 . The ratio of the volatile compounds exceeds unity in the medium size particle range and is lowest at the extremes of particle size (Figures 3 through 5). The less volatile compounds, such as neophytadiene and norphytene are more uniformly distributed throughout the entire particle size range (Figures 6 and 7). Copper, the only inorganic species studied, exists in larger concentrations in the small and large particles than it does in the medium size particles (Figure 8). Obviously, if a number of organic compounds are more highly concentrated in the medium size particles than in the small or large particles, many compounds in addition to copper must exhibit opposite behavior to give the observed TPM distribution. The distribution of nicotine obtained in this work is in general agreement with the results of previous studies $(8,10)$. Owen, Woodman, and Westcott reported wider ranges of nicotine concentration for different size particles than we found. They reported nearly two times the nicotine concentration in the $0.6 \mu$ particles than they have found in the $0.2 \mu$ particles (8). The same authors reported that the size distribution of neophytadiene closely resembled the distribution of TPM.

The particle size distribution of TPM in cigarette smoke with and without a filter is shown in Figure 9. The average particle size of the filtered smoke is smaller than that of the unfiltered smoke. The percentage of $0.75 \mu$ particles filtered is greater than the percentage of $0.5 \mu$ particles filtered. This trend is in agreement with previous findings of Keith and Derrick who found a preferential reduction in the numbers of larger particles by a filter (2). Our data are also in agreement 
Figure 9. Size distributlon of TPM.

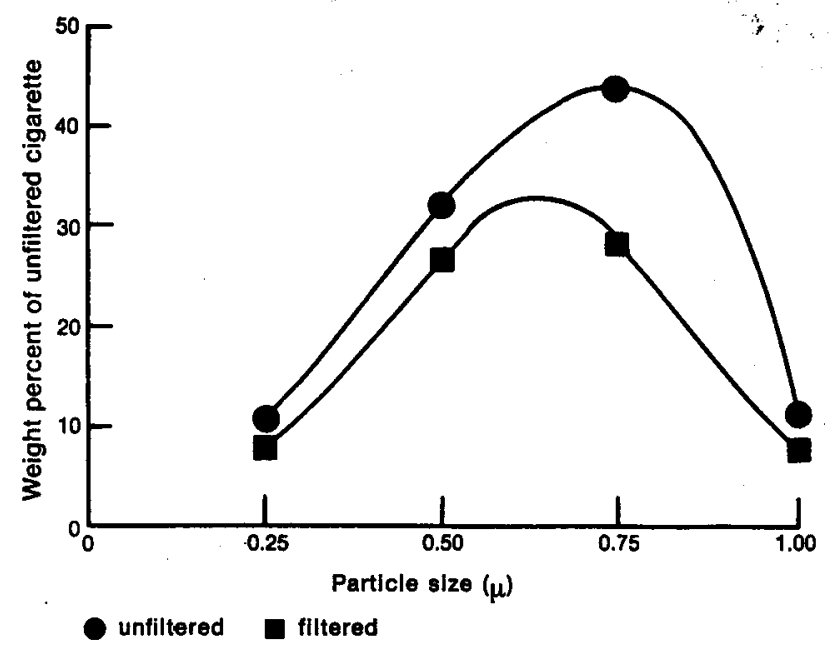

with the theoretical filtration curves by fibrous filters as a function of aerosol particle size at a flow rate of $17.5 \mathrm{~cm}^{3} / \mathrm{s}$. Filtration efficiency is lowest for the medium size particles and increases in both the direction of increasing and decreasing particle sizes. Therefore, the TPM on the first and fourth plates of the cascade impactor should have been reduced by a filter to a larger extent than was observed. Because the weights of smoke particles in the $0.25 \mu$ and $1.0 \mu$ ranges are extremely low, it is likely that the precision of the method was not sufficient to accurately describe the curve at the extremities of particle size.

The particle size distribution of nicotine in cigarette smoke with and without a filter is shown in Figure 10. Again the average particle size of the filtered nicotine is smaller than that of the unfiltered nicotine. A greater percentage of the $0.75 \mu$ particles are filtered than are the $0.5 \mu$ particles.

It is evident from Figure 10 that a larger percentage of nicotine is present in the medium size particles, which are most difficult to filter, than is present in the

Figure 10. Slze distribution of nicotine.

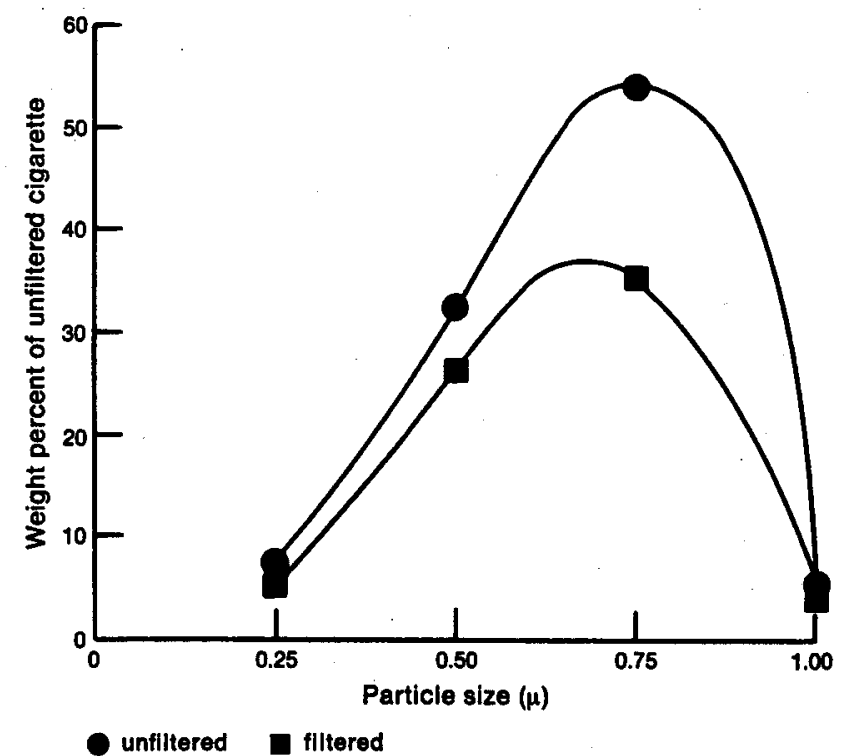

large, or small particles. Keith and Derrick estimated that the $0.3 \mu$ particles are filtered least efficiently (9); data from our laboratory indicate the particles which are most difficult to remove are 0.5 to $0.6 \mu$ in diameter. A calculation of the theoretical filtration of nicotine was made based on the following data and assumptions: The distributions of TPM and nicotine were taken from Table 1, the particle size/filtration efficiency curve was taken from previous work in our laboratory, and a filter which removes 40\% TPM was assumed. The filtration efficiency calculated for nicotine in this hypothetical case was $39 \%$. Although this lower efficiency is in the expected direction, it is neither statistically significant, nor does it account for the differences normally observed for the filtration of TPM and nicotine by cellulose acetate filters. Typically, a cellulose acetate filter removes $40 \%$ TPM and 36 or $37 \%$ nicotine from the smoke of a blended tobacco cigarette with a smoke $\mathrm{pH}$ of 5.5 to 5.8. The high concentration of nicotine in the medium sized aerosol particles which are most difficult to filter may contribute slightly to this phenomenon. However, Curran and Kiefer showed that a substantial amount of nicotine which is initially trapped by a filter is later eluted into the mainstream smoke during subsequent puffs. The TPM which is initially trapped by a filter is not eluted to a significant extent (15).

It may be concluded that even though significant differences in the composition of smoke with particle size exist, it is unlikely that selective filtration based on the removal of a particular particle size can be achieved.

\section{SUMMARY}

If the distribution of specific smoke components with respect to particle size were significantly different than the size distribution of particulate matter, a compound or group of compounds might be selectively removed by the selective filtration of a given particle size. Various techniques have been used to determine the particle size distribution of a few smoke components. Berner and Marek used a Goetz aerosol spectrometer to determine the size distribution of potassium in smoke; and Owen, Westcott and Woodman used a conifuge to examine the distribution of three smoke components. In the present work, a cascade impactor was used to separate smoke particles into four fractions of 0.25 to $1.0 \mu$ in diameter based on the principle that particles in a moving airstream impact on a slide placed in their path, if their momentum is sufficient to overcome the drag exerted by the airstream. The particle size distribution of five organic compounds: indole, nicotine, diethyl phthalate, norphytene, and neophytadiene were determined. These size distributions were compared to the distribution of total particulate matter (TPM) and the following observations were made:

1. All compounds were distributed in a pattern similar to that of TPM. Therefore, the selective filtration of 
a given compound by selective filtration of a given particle size is probably unfeasible.

2. The concentrations of indole and nicotine were higher in the medium-size particles $(0.5$ to $0.75 \mu)$ than in the small or large particles.

3. It is known that cellulose acetate filters are more efficient for the filtration of small and large particles than they are for medium-size particles. Therefore, the high concentration of nicotine in the medium-size particles may contribute to the slightly higher filtration efficiency these filters have for the TPM than they have for nicotine.

\section{ZUSAMMENFASSUNG}

Wenn sich die Verteilung bestimmter Rauchbestandteile hinsichtlich der Partikelgröße von der Größenverteilung der Partikelphase wesentlich unterschiede, könnte eine Verbindung oder eine Gruppe von Verbindungen durch selektives Ausfiltern einer gegebenen Partikelgröße selektiv entfernt werden. Zur Bestimmung der Partikelgrößenverteilung einiger Rauchinhaltsstoffe sind verschiedene Techniken angewandt worden. Berner und Marek bestimmten die Größenverteilung von Kalium im Rauch mit einem Goetz-Aerosolspektrometer, und Owen, Westcott und Woodman benutzten eine Aerosolzentrifuge ("conifuge") zur Untersuchung der Verteilung von drei Rauchbestandteilen. In der vorliegenden Arbeit werden die Rauchpartikel in vier Fraktionen mit einem Durchmesser von 0,25 bis $1,0 \mu$ mit Hilfe einer Apparatur ("cascade impactor") aufgeteilt, deren Wirkungsweise das Prinzip zugrunde liegt, daß Partikel in einem bewegten Luftstrom auf eine in ihrem Weg befindliche Fläche aufschlagen, wenn ihre Bewegungsenergie zur Uberwindung des vom Luftstrom ausgehenden Widerstandes ausreicht. Die Partikelgrößenverteilung der folgenden fünf organischen Verbindungen wurde bestimmt: Indol, Nikotin, Diäthylphthalat, Norphyten und Neophytadien. Bei einem Vergleich der dabei ermittelten Größenverteilungen mit der Verteilung der Gesamtpartikelphase (TPM) wurde folgendes beobachtet:

1. Alle Verbindungen waren in einem ähnlichen Muster verteilt wie die Gesamtpartikelphase. Die selektive Filtration einer bestimmten Verbindung durch selektive Filterung einer bestimmten Partikelgröße ist daher wahrscheinlich nicht möglich.

2. Die Konzentrationen von Indol und Nikotin waren in den Partikeln mittlerer Größe $(0,5-0,75 \mu)$ höher als in den kleinen und großen Partikeln.

3. Bekanntlich haben Celluloseacetatfilter für kleine und große Partikel ein höheres Filtrationsvermögen als für Partikel mittlerer Größe. Die hohe Konzentration des Nikotins in den mittelgroßen Partikeln könnte daher dazu beitragen, daß diese Filter eine etwas höhere Filterwirksamkeit für die Gesamtpartikelphase haben als für Nikotin.

\section{RESUME}

Si la distribution de constituants spécifiques de la fumée de tabac par rapport aux dimensions des particules était, d'une manière significative, différente de la distribution dimensionnelle de la matière particulaire, un composé ou un groupe de composés pourrait être éliminé d'une manière sélective par une méthode de filtration sélective de dimension donnée. Des techniques diverses ont été employées pour déterminer la distribution dimensionnelle des particules de quelques constituants de fumée. Berner et Marek ont employé un spectromètre à aérosol de Goetz. pour établir la distribution dimensionnelle du potassium dans la fumée. Owen, Westcott et Woodman ont employé un appareil centrifugeur (*conifugew) pour examiner la distribution de trois constituants de fumée. Dans le présent travail une cascade d'impact a été employée pour séparer des particules de fumée en quatre catégories dimensionnelles comprises entre les diamètres de 0,25 à $1,0 \mu$. Cette méthode est basée sur le principe que des particules suspendues dans un jet d'air vont impacter une plaquette située dans leur cours si leur moment est suffisant pour vaincre la résistance exercée par le jet d'air. La distribution dimensionnelle des particules a été déterminée pour cinq constituants organiques: l'indol, la nicotine, la diéthyle-phtalate, la norphytène et la néophytadiène. Ces distributions dimensionnelles ont été comparées avec la distribution de la matière particulaire totale (TPM) et les observations suivantes ont été faites:

1. Tous les constituants sont distribués d'une manière semblable au TPM. Donc, la filtration sélective d'un composé spécifique par la filtration sélective de particules de certaine dimension n'est probablement pas faisable.

2. La concentration d'indol et de nicotine était plus élevée dans les particules à dimensions moyennes $(0,5$ à $0,75 \mu$ ) que dans les particules à petites ou à grosses dimensions.

3. On sait que les filtres d'acétate de cellulose sont plus efficaces pour la filtration de petites et de grosses particules que pour les particules aux dimensions intermédiaires. Donc, la grande concentration de nicotine dans les particules à dimensions moyennes peut contribuer à l'efficacité de filtration un peu plus élevée qu'ont ces filtres pour le TPM que pour la nicotine.

\section{REFERENCES}

1. Warner, B. R., R. L. Wells, and M. E. Hobbs: 7th Tobacco Chemists' Research Conference, Louisville, Ky., 1952.

2. Keith, C. H., and J. C. Derrick: Tob. Sci. 5 (1961) 84.

3. Holmes, J. C., J. E. Hardcastle, and R. I. Mitchell: Tob. Sci. 3 (1959) 148.

4. Leonard, R. E., and J. E. Kiefer: Tob. Sci. 16 (1972) 65.

5. Overton, J. R.: Tob. Sci. 11 (1967) 58. 
6. Okada, T., and K. Matsunuma: J. Colloid and Intèrface Sci. 48 (1974) 461.

7. Hill, C. A., and P. I. Adams: Coresta Symposium held in Montreux, Switzerland, in September 1974.

8. Owen, W. C., D. T. Westcott, and G. R. Woodman: 'Tobacco Chemists' Research Conference, Philadelphia, Pa., 1969.

9. Keith, C. H., and J. C. Derrick: Tob. Sci. 4 (1960) 116.

10. Berner, A., and J. Marek: Fachliche Mitt. Osterr. Tabakregié Heft 7, 118, 1967.

11. Jones, R. T., W. G. D. Lugton, S. R. Massey, and R. B. Richardson: Beitr. Tabakforsch. 8 (1975) 89.

12. Mitchell, R. I., and J. M. Pilcher: Ind. Eng. Chem. 51 (1959) 1039.
13. Smit, H.: Proceedings of the Coresta (General Assembly) / 26th TCRC Joint Conference held in Williamsburg, Va., U.S.A., in October 1972, Coresta Information Bulletin p. 114.

14. Sloan, C. H.: Private communication.

15. Curran, J. G., and J. E. Kiefer: Beitr. Tabakforsch. 7 (1973) 29.

\section{Adenowledgements}

The authors thank Mr. Phil McConnell for bis assistance in the atomic absorption analyses.

The authors' address:

Research Laboratories, Tennessee Eastman Company, Kingsport, Tennessee, 37662, U.S.A. 